\title{
A VERDADE SOBRE OS CADERNOS NEGROS
}

\author{
José Reinaldo F. Martins Filho *
}

\begin{abstract}
VON HERRMANN, Friedrich-Wilhelm; ALFIERI, Francesco. Martin Heidegger: la verità sui Quaderni neri. Brescia: Morcelliana, 2016, 464p. ISBN 978-88-372-2928-3.
\end{abstract}

Não é difícil admitir, por parte de críticos ou admiradores, que o pensamento de Martin Heidegger é, certamente, um dos episódios mais importantes da filosofia nas últimas décadas, como demonstra o seu legado e influência nas mais diferentes frentes do conhecimento, sejam elas a Teologia, a Psicologia, a Psiquiatria, as Artes, a Arquitetura, como também a própria Filosofia - especialmente em suas tendências fenomenológica e hermenêutica. Porém, com a mesma intensidade com que assentimos a essa constatação, é preciso igualmente admitir que o trato com a herança heideggeriana também suscitou severas incompreensões e, mais que isso, o pejorativo uso político de fragmentos aleatoriamente pinçados de sua obra. Ao que parece, o próprio Heidegger esteve consciente desta possibilidade, como escrevera ao seu irmão Fritz Heidegger em 17 de dezembro de 1945: "Caro Fritz! [...] Você tem razão. O meu nome é uma questão política, de um modo ou de outro. Todos falam de mim e ninguém reflete - exceto os poucos que permanecem em silêncio. Nos alemães prevalece uma terrível condenação" 1 .

Para dizermos francamente, trata-se da desconfiança, suscitada por diferentes vias, acerca do envolvimento entre Heidegger e o regime Nacional

\footnotetext{
* Doutor em Ciências da Religião e Professor no Programa de Pós-Graduação em Ciências da Religião - Stricto Sensu - da Pontifícia Universidade Católica de Goiás. Doutorando em Filosofia pela Universidade Federal de Goiás. Coordenador do curso de Bacharelado em Filosofia do Instituto de Filosofia e Teologia de Goiás (IFITEG).

${ }^{1}$ Martin Heidegger; Fritz Heidegger. Carteggio - 1930-1949. A cura di F.-W. von Herrmann e F. Alfieri. Brescia: Morcelliana, 2018. p. 150.
} 
Socialista, cujas consequências catastróficas foram sentidas particularmente na Alemanha, de onde se alastraram para todo o globo. É verdade que, como todo professor alemão em uma instituição de ensino pública, Heidegger também precisou se filiar ao partido nazista - e todos podemos saber o que significaria devolver a carteira de identificação do partido naquele contexto, mesmo após a constatação, tardia para a maioria dos alemães, das reais intenções de Hitler. Por outro lado, contudo, também é preciso considerar qual foi o real alcance deste envolvimento, o que, definitivamente, não pode ser sustentado sob o ponto de vista da ideologia antissemita.

Como é conhecido por todos, logo nos primeiros anos de Hitler no poder os professores judeus ou de origem judaica começaram a ser afastados de seus cargos. A vista disso, já em suas primeiras semanas como reitor Heidegger precisou lidar com um contexto áspero. Chegou a interceder por alguns professores, a fim de que se mantivessem em seus cargos, ou, caso isso não fosse possível, ao menos conseguissem postos de estabilidade em outras universidades europeias. Esse foi o caso de Eduard Fraenkel, catedrático de filologia, Georg von Hevesy, professor de físico-química e, até mesmo, Werner Brock, então assistente pessoal de Heidegger ${ }^{2}$. Nem todas as tentativas, contudo, lograram êxito, motivo pelo qual muitos precisaram deixar a Alemanha, como forma de assegurarem suas vidas e a vida de seus familiares. Entre tantos outros, este foi o caso de Hannah Arendt, ex-aluna e amante de Heidegger durante seus anos em Marburg.

Apesar da dificuldade dos anos de guerra, permanecendo duplamente questionado pela opinião pública e pelo partido nazista, os anos seguintes reservavam desafios ainda mais duros para o então professor de Freiburg. A princípio Heidegger fora afastado de suas funções como docente apenas temporariamente, enquanto transcorresse o seu processo de desnazificação. Este episódio é retratado pelo autor em uma carta ao seu irmão, datada de 21 de fevereiro de 1946: "Caro Fritz! Desde alguns dias estou aqui para tomar distância de tudo. Em Freiburg fui atormentado quase todos os dias" ${ }^{3}$. O que era provisório, entretanto, estendeu-se como sentença definitiva, isto é, não apenas como a proibição de ensinar publicamente, mas também de manter qualquer contato com a Universidade (o que durou de 1945 a 1951). Mesmo sua biblioteca pessoal foi repetidas vezes considerada como patrimônio a ser confiscado, dada a "periculosidade iminente" de seu proprietário.

Curiosamente, como dito de relance, a desconfiança nutrida por parte dos desnazificadores não era muito diferente daquela de alguns membros do

\footnotetext{
${ }^{2}$ Cf. SAFRANSKI, Rüdiger. Heidegger: um mestre para a Alemanha. São Paulo: Geração Editorial, 2005. p. 303-304.

${ }^{3}$ Martin Heidegger; Fritz Heidegger. Carteggio - 1930-1949. A cura di F.-W. von Herrmann e F. Alfieri. Brescia: Morcelliana, 2018. p. 151.
} 
partido, especialmente os integrantes de suas altas instâncias deliberativas. Por um lado, Heidegger nunca fora levado realmente a sério pelos nazistas. Ao contrário, até mesmo o barraram de integrar a comitiva alemã que iria participar do Congresso Internacional de Filosofia em Paris, em 1937, por conta de sua difícil subordinação. Por outro, como pensador livre que foi, Heidegger realmente incomodou: a nazistas e não nazistas, a cristãos e não cristãos, a judeus e não judeus, à filosofia como um todo. Isso porque a tenacidade de seu pensamento obriga ao abandono, à recusa das categorias como utilizadas até então, motivo pelo qual nem sempre fora compreendido. Ainda assim, deixou sua marca e o legado de um pensamento completamente aberto à ressonância do ser na história, chegando aos nossos dias como um dos mais importantes capítulos de toda a Filosofia - e isso para dizermos com Lévinas, um de seus críticos ${ }^{4}$.

Ocorre que a suspensão das proibições contra Heidegger, proclamada em 1951, e, mesmo, a morte do autor, em maio de 1976, não foram suficientes para silenciar definitivamente as desconfianças sobre o "propósito antissemita" de seu pensamento. A primeira grande reação viria a público em 1987, com o trabalho do chileno Víctor Farías, titulado Heidegger e o Nazismo - com tradução brasileira de 1988. Em seu livro Farías apresenta o que seriam fundamentos para a identificação dos princípios nazistas inerentes ao pensamento heideggeriano como um todo, sendo Heidegger apontado como uma espécie de "guru" do antissemitismo na Alemanha posterior a Friedrich Nietzsche. Essa, aliás, parece ter sido a deixa para o francês Emmanuel Faye que, em 2005, também pleiteava um espaço no debate, com seu livro Heidegger, em que indica o que seriam os vestígios antissemitas do pensamento heideggeriano, particularmente a partir dos seminários de Heidegger sobre Nietzsche, realizados entre 1933 e 1935. Em ambas as ocasiões - tanto em 1987, quanto em 2005 - autores de importância internacional, entre os quais alguns que conheceram e se relacionaram pessoalmente com Martin Heidegger, sentiram-se no dever moral de se manifestar. Entre esses destacam-se o envolvimento de Hans-Georg Gadamer e, mais recentemente, de François Fédier, ambos apontando as fragilidades presentes nas críticas levantadas e rebatendo com abundante documentação e honesta acuidade interpretativa toda e qualquer suspeita sobre um direcionamento conciliador entre Heidegger e o nazismo.

Ocorre que, passados mais de quinze anos desde as últimas maiores repercussões do assim chamado "caso Heidegger", fomos surpreendidos por uma série de ataques emanados por Peter Trawny em ocasião da publicação dos Schwarze Hefte - Cadernos negros - diários de capa preta em que Heidegger inscrevia pensamentos e anotações pessoais, marginal-

${ }^{4}$ LÉVINAS, Emmanuel. Ética e infinito: diálogos com Philippe Nemo. Tradução de João Gama. Lisboa: Edições 70, 2000. p. 29. 
mente à composição de seu pensamento. Infelizmente o caso de Trawny não se mostrou isolado, em particular quando testemunhamos no Brasil a recente publicação - de 2017 - do livro de Víctor Farías, por ora com o título Heidegger e sua herança. Como se não bastasse a suspeita da dívida de Heidegger com relação ao tema de seu envolvimento com o nazismo, desta vez o autor insinua o que seria a herança da obra heideggeriana como pressuposto para os fundamentalismos religiosos no Oriente, as revoluções das esquerdas latino-americanas, as ditaduras populistas, entre outros. São verdadeiramente surpreendentes - em sentido negativo - as palavras interpostas pelo apresentador da edição brasileira, João Ricardo Moderno, o então presidente da Academia Brasileira de Filosofia (uma entidade com inclinação para o pensamento conservador), algumas das quais transcrevemos: "A lavanderia Heidegger é uma máquina cega e mortal disseminada no mundo todo. [...] Há, portanto, uma desonestidade intrínseca no heideggerianismo, uma cínica demonstração de ocultação de cadáver". Esse trecho é completado um pouco adiante, desta vez com referência aos estudiosos do pensamento heideggeriano, dizendo que estes: “[...] não percebem nem o pensamento oculto, nem o explícito, por uma estratégia política de salvaguardar o prestígio do Führer da filosofia. Desabando Heidegger, desaba a carreira universitária de todos" ${ }^{\prime \prime}$.

Ao nos darmos conta da ferocidade dessas palavras, esperamos defrontarmo-nos com um argumento ao menos comprovado e bem sustentado de um ponto de vista documental, sobretudo com base em fontes primárias a respeito do que se pleiteia desde o título e a apresentação. Não é, contudo, o que encontramos. Com exceção de passagens remotas e mal contextualizadas do pensamento heideggeriano, prevalecem impressões difundidas por identidades igualmente conhecidas por seu conservadorismo, relegando todo o volumoso calhamaço ao nível das discussões que diuturnamente se estendem nas redes sociais e demais espaços para a "opinião pública" - o que, nem de longe, pode ser aproximado do rigor requerido pelo fazer acadêmico, especialmente em filosofia, tema sobre o qual Heidegger mesmo chegou a dizer entre 1928 e 1929: "como a filosofia tem essa inclinação livre e é por isso mesmo uma livre possibilidade fundamental da existência, ela se encontra diante do perigo de ser mal utilizada" ${ }^{\prime 6}$.

Tudo o que dissemos até aqui tem em vista apresentar o panorama atual, que guarda muito em comum com o ambiente a partir do qual emergiram as acusações de Peter Trawny. Essas constituem, em linhas gerais, o fio da meada que motivou o desdobramento da importante obra que tomamos por análise, já com repercussão em uma série de países, traduzida para cinco idiomas e, num período breve, também disponível em português -

\footnotetext{
${ }^{5}$ FARÍAS, Vítor. Heidegger e sua herança. São Paulo: É Realizações, 2017. p. 34-35.

${ }^{6}$ HEIDEGGER, Martin. Einleitung in die Philosophie. Frankfurt am Main: Vittorio Klostermann, 1996. (Gesamtausgabe 27). p. 26.
} 
graças ao esmero dos professores Juvenal Savian Filho e Clio Tricarico. Referimo-nos, portanto, ao valioso trabalho desenvolvido por Friedrich-Wilhelm von Herrmann e Francesco Alfieri em Martin Heidegger: la verità sui Quaderni neri, publicado em 2016 pela editora Morcelliana, de Brescia e, simultaneamente, na Alemanha. O livro, como pretendemos apontar, constitui-se como um contraponto às acusações de Trawny, elevando-se à condição de um salutar instrumento de leitura do "caso Heidegger" e de compreensão do que está exposto nos Cadernos negros.

Dada a sua proximidade com o professor von Herrmann - o último secretário de Heidegger, responsável, segundo menção em testamento, pela publicação da obra completa do autor - Francesco Alfieri conta ter recebido uma série de quatorze páginas manuscritas para leitura e análise. A princípio não sabia que se tratava de textos de Heidegger e, portanto, pôs-se a estudá-las unicamente a partir de uma perspectiva textual. Em resposta a von Herrmann, apontou a necessidade de conhecer mais profundamente a linguagem própria do autor daquelas páginas, conhecimento sem o qual a interpretação estaria sujeita a controvérsias e incompreensões. Foi aquele o momento em que soube se tratar de textos de Martin Heidegger, a partir dos quais Peter Trawny havia desenvolvido seu argumento. A análise mais aprofundada dos fragmentos à luz do pensamento heideggeriano, no entanto, revelou que os mesmos não apenas não constituíam argumentos válidos sobre o "antissemitismo" de Heidegger, como, ao contrário, poderiam ser usados para desqualificar o trabalho de Trawny, que não partiu de uma adequada interpretação das fontes - nalguns casos até corrompendo originais e modificando expressões.

A oportunidade de escrever um livro sobre o assunto surgiu, por isso, não unicamente como uma forma de defesa da reputação de Heidegger, mas em prol de salvaguardar a continuidade de uma tradição - a tradição fenomenológica - para a qual o rigor investigativo é um traço determinante. Eis, pois, o sentido do subtítulo da obra: a verdade sobre os Cadernos negros. Verdade aqui não como o princípio hegemônico e previamente imposto, como anulação de um eventual contraponto, mas como a meta derradeira de toda atividade intelectual coerente e comprometida; o resultado de um esforço investigativo notadamente ausente nas suspeições de Trawny, Farías e Faye. O trabalho de Trawny merecia uma resposta, e foi o que fizeram von Herrmann e Alfieri em seu livro, o qual podemos dividir em quatro partes: a) na primeira von Herrmann descreve como conheceu Trawny e sua indicação como editor dos Cadernos negros; b) na segunda - e mais longa - Francesco Alfieri desenvolve uma cuidadosa leitura dos fragmentos um por um, contrastando-os com passagens retiradas das grandes obras de Heidegger; c) na terceira os autores apresentam uma importante fonte documental, em que constam cartas pessoais de von Herrmann trocadas com Gadamer, Heinrich Heidegger, além de uma referência a Edith Stein; d) finalmente, o livro se encerra com algumas contribuições sobre a cons- 
tituição ôntico-histórica e metafísica do pensamento heideggeriano e um panorama do uso instrumentalizado do "caso Heidegger" pelos meios de comunicação na Itália.

O texto inicial, escrito por von Herrmann, é verdadeiramente esclarecedor. Começa por situar o projeto do livro a partir de sua interlocução com Francesco Alfieri, mas também revela muito de seu papel ao longo das últimas décadas na elaboração das obras completas (Gesamtausgabe) de Heidegger. Faz-nos, sobretudo, tomar conhecimento da indicação feita por ele próprio de Peter Trawny como editor escolhido para realizar o trabalho dos Cadernos negros. Como é sabido por alguns, o trabalho de edição das obras de Heidegger não é uma tarefa fácil. O editor deve se ocupar por transcrever os textos manuscritos, simultaneamente traduzindo-os do dialeto utilizado por Heidegger para o alemão convencional. Apenas após esta etapa inicia-se o trabalho de edição das provas, até que se obtenha a publicação. Alguns volumes, por exemplo, foram editados a partir das lições de Heidegger, num constante cotejo entre suas próprias anotações e as anotações de alguns de seus alunos. Parte do trabalho de datilografia foi realizado pelo irmão Fritz Heidegger, mas muitos textos, como era o caso das anotações nos Cadernos negros, ainda deveriam por ser organizados.

Segundo o professor von Herrmann, além disso, a indicação de Trawny levou em conta sua dedicação em outros trabalhos, mas, sobretudo, a situação em que se encontrava, passando por dificuldades profissionais e, até mesmo, financeiras. Embora o conhecesse desde 1995, por conta da publicação de seu trabalho de pesquisa sobre Heidegger, von Herrmann não poderia prever a sua atitude quando da publicação dos Cadernos. Sobre isso, podemos ler a seguinte admoestação: "enquanto coordenador filosófico da edição completa da obra designado por escrito por Martin Heidegger, e enquanto seu assistente privado durante os seus últimos quatro anos de vida, recomendei aos administradores do legado o atual curador dos Cadernos negros somente como editor dos textos, não como seu intérprete"7. Ocorre que, passada a fase de organização dos manuscritos e sua publicação, Trawny veio a público com uma série de interpretações sobre a vinculação de Heidegger com o nazismo e, para além disso, a respeito de uma pretensa contaminação antissemita em todo o pensamento heideggeriano.

Sobre isso, como recorda o professor von Herrmann, do total de 1250 páginas em formato $\mathrm{A} 4$, as referências de Heidegger aos judeus, ao nazismo, a Hitler ou a outros temas correlatos, resumem-se a 14 páginas. $\mathrm{O}$ maior problema, porém, é que Peter Trawny, ao elaborar sua interpretação pessoal, reuniu todas elas seguidamente, sem respeitar os contextos em que se inseriam. Além disso, aproximou-as de outros momentos esparsos

${ }^{7}$ F.-W. von Herrmann - F. Alfieri. Martin Heidegger: la verità sui Quaderni neri. Brescia: Morcelliana, 2016. p. 35. 
em que apareceram na obra de Heidegger como um todo. Nesse sentido, podemos supor o que pode significar, por exemplo, reunir num mesmo texto as referências de Heidegger aos judeus e, em seguida, ao conceito de Selbstvernichtung, isto é, o "autoaniquilamento", expressão que o autor utilizou para referir-se ao domínio do pensamento calculante, da técnica, à ausência do pensar estabelecida até mesmo dentro da própria filosofia.

De outro lado, também é curioso que Peter Trawny não tenha dado a mesma ênfase às tantas vezes em que nos Cadernos negros Heidegger se referiu de forma condenatória a Hitler e ao nazismo, chamando-os de catástrofe, de irracionalidade e por outras adjetivações demeritórias. Daí, então, que apenas uma análise responsável e aprofundada das páginas que constituem as anotações heideggerianas poderia retirar eventuais dubiedades, revelando o verdadeiro sentido das expressões e colocando-as dentro de seu universo semântico específico. Paralelamente, isso contribuiria para o reconhecimento do limite inerente à abordagem de Trawny. Esse foi o esforço de Francesco Alfieri, que, por dias a fio, passou e repassou aqueles registros com o intuito de extrair deles o seu real conteúdo. Não se trata, portanto, como sempre recorda Alfieri, de realizar uma defesa de Heidegger. Caso se encontrasse alguma evidência concreta sobre o seu envolvimento com princípios nazistas, Alfieri e von Herrmann seriam certamente os primeiros a tornar isso público. Ocorre que não encontraram, o que também precisa ser dito em claro e bom som.

O trabalho que podemos chamar de "arqueologia conceitual" e, por isso, a parte mais densa da publicação, embora tenha estado a cargo do professor Alfieri, contou com a contínua e sempre próxima colaboração de von Herrmann. A atividade de análise concentrou-se nos Überlegungen, isto é, nas Reflexões, e nos Anmerkungen, Anotações, presentes nos volumes 94 e 95 da Gesamtausgabe. De maneira geral, dizem os professores, não há nenhuma novidade significativa do ponto de vista da compreensão do pensamento heideggeriano nos Cadernos, mas apenas apontamentos soltos que servem para um maior conhecimento de questões relativas à vida pessoal do filósofo, à sua relação com o seu tempo e com algumas personalidades importantes da época, como é o caso de Edmund Husserl. Por exemplo, nas Anotações $V$ (52-54) descobrimos uma referência explícita de Heidegger a Husserl, a qual vale a pena transcrevermos, por se tratar de uma importante fonte sobre a relação entre ambos: “Desde quando Husserl em 1930/31 tomou publicamente posição contra mim em conferência, já quase como manifestações (Berlim e Frankfurt), e refutou o meu trabalho como não sendo filosofia [...] eu passei por cima e me afastei".

Explicações sobre o período do reitorado também são manifestas de forma abundante, como nas Anotações III (57-58): "Talvez um dia alguém entenderá que no discurso do reitorado de 1933 faz-se a tentativa de se pensar antecipadamente este processo de cumprimento da ciência no final do pen- 
samento, de reportar no pensamento o saber enquanto saber essencial, mas não de abandoná-lo nas mãos de Hitler". As constantes menções críticas tanto pessoalmente dirigidas a Hitler quanto ao partido como um todo e ao seu ideal são igualmente frequentes em outros momentos das Anotações, como: "[...] a essência irresponsável com a qual Hitler enfureceu toda a Europa" (III [46-47]); "[...] o antissemitismo é tão louco e reprovável quanto a intervenção sanguinária [...] do cristianismo contra os pagãos" (II [77]); "[...] Hitler tornou-se uma catástrofe" (III [47]). É certamente impossível nesse momento reproduzirmos e, mesmo, aprofundarmos todas as passagens críticas quanto à relação entre Heidegger e o Nacional Socialismo, assim como também não nos cabe desenvolver apontamentos sobre o uso dos conceitos heideggerianos como foram tomados por Trawny. De nossa parte, contentamo-nos em apenas recomendar a leitura deste que é certamente um dos mais importantes trabalhos já escritos sobre o tema, especialmente por seu vigor investigativo, contato com as fontes e apresentação de provas.

Aliás, já a análise de Francesco Alfieri poderia ser tomada como suficiente para contrabalancear as críticas de Peter Trawny. Não obstante, à contextualização e análise de von Herrmann e Alfieri, unem-se o último capítulo da obra, bem como os anexos que o seguem de perto. Na seção de cartas os autores começam por recobrar uma menção de Edith Stein, em carta dirigida ao seu amigo Roman Ingarden, em 25 de dezembro de 1931, sobre a atenção dispensada pelo professor Heidegger quando lhe remetera seu manuscrito Potenz und Akt. Além disso, recordam que a própria Stein inseriu um Anexo dedicado ao pensamento de Heidegger em sua obra prima, Endliches und ewiges Sein. Acaso o teria feito se repousasse sobre Heidegger a menor desconfiança de ter-se comprometido com o nazismo ou com o antissemitismo em seu pensamento? Os autores referem-se ao exemplo de Edith Stein por conta de sua moralidade incontestável. No entanto, ainda poderíamos mencionar Hannah Arendt e Elisabeth Blochmann entre outras ex-alunas próximas e de origem judia que, para além de amantes, tiveram com o autor verdadeira amizade até o fim de suas vidas, como sabemos por suas cartas. Tal afirmação, aliás, é sustentada pelo segundo filho de Heidegger, Hermann Heidegger, que também participou da edição com uma carta, em que afirma: "[...] Por toda a vida Martin Heidegger manteve estreitos laços de amizade [...] com judeus [...]. Não podemos nos esquecer que muitos estudantes judeus mantiveram contatos com Martin Heidegger". Os argumentos do filho atuam como uma espécie de arremate à série de cartas pessoais de von Herrmann, que também tentam expressar a seriedade com que o tema do nazismo foi tratado não somente pelo próprio filósofo, mas pelos que lhe foram mais próximos.

Para concluir, é preciso dizer que os pontos elencados acima nem de longe podem expressar a densidade e, igualmente, a qualidade do material disponível à pesquisa sobre Heidegger. Embora tenhamos adiantado que a tradução para o português, que já está em curso, chegará em breve às mãos 
de leitores brasileiros, dado tratar-se de uma obra originalmente publicada em 2016, não pudemos nos eximir da responsabilidade de divulgá-la a um horizonte mais amplo da comunidade filosófica no Brasil. Enquanto as condições exteriores tomam um formato semelhante àquele da Alemanha na década de 1930, não somente no Brasil, mas como uma tendência mundial, devemos ter a capacidade e, ao mesmo tempo, a lucidez de manifestar a nossa postura crítica, a denúncia de que a morte da liberdade equivale à aniquilação do pensamento. Nesse sentido, não apenas é necessário "sermos livres para conhecer", à revelia de quaisquer impedimentos circunstanciais - a proibição de livros e conteúdos, como noutros tempos, o corte de verbas das universidades públicas - mas, igualmente, "conhecermos para sermos livres", isto é, tomarmos seriamente a tarefa que nos é legada, dedicando nossos esforços em prol de nos aproximarmos cada vez mais da verdade que se acena e se furta, como na feliz metáfora da "terceira margem do rio". Se é verdade que um filósofo pode ser reconhecido pela extensão de seu legado, alçando-se como estrela na constelação geral do mundo dos humanos, nesse mesmo impulso percebemos o abismo diametral entre iniciativas que nada mais significam que uma espécie de caricatura do real exercício do pensar e aquelas que, diversamente, podem categorizá-lo plenamente. De nossa parte, inserimos o trabalho de Friedrich-Wilhelm von Herrmann e Francesco Alfieri no segundo grupo. 